\title{
DDAVP test for estimation of renal concentrating capacity in infants and children
}

\author{
A. S. ARONSON and N. W. SVENNINGSEN \\ From the Department of Paediatrics, University Hospital, Lund, Sweden
}

\begin{abstract}
Aronson, A. S., and Svenningsen, N. W. (1974). Archives of Disease in Childhood, 49, 654. DDAVP test for estimation of renal concentrating capacity in infants and children. A new method for the estimation of the renal capacity to concentrate urine is described. Intranasal administration of DDAVP (1-deamino-8-D-arginine vasopressin), a synthetic analogue of the antidiuretic hormone, has been used for the measurement of urine concentrating performance in 79 children and 25 infants. By comparative studies of different doses of intravenous and intranasal administration of DDAVP, a standard procedure has been elaborated with the intranasal administration of $20 \mu \mathrm{g}$ in children and $10 \mu \mathrm{g}$ in infants.

The maximum urine osmolality values obtained with the DDAVP test are compared to those achieved with other renal concentration tests, i.e. dehydration test and pitressin test. The present investigation shows that intranasal administration of DDAVP, with no or only moderate short-term fluid restriction, yields urine osmolality values comparable to those after 22 hours of prolonged dehydration, and higher than those after combined pitressin and fluid deprivation test. No side effects have been observed with the procedure described.
\end{abstract}

Different procedures for measuring the urine concentration capacity of the kidneys have been widely used, e.g. prolonged dehydration tests (Edelmann et al., 1967; Miles, Paton, and de Wardener, 1954; Polàček et al., 1965), pitressin tests (Jones and de Wardener, 1956; West, Traeger, and Kaplan, 1955), or combined pitressin and fluid deprivation tests (Winberg, 1959). Higher urine osmolality is obtained after prolonged dehydration than after pitressin administration alone (Miles et al., 1954). However, the addition of fluid deprivation will reinforce the pitressin effect upon the urine concentration performance (Winberg, 1959).

DDAVP (1-deamino-8-D-arginine vasopressin) is a synthetic analogue of the antidiuretic hormone. It can be given in doses producing maximum antidiuretic effect without the disturbing side effects of pressor type (Anderson and Arner, 1972; Aronson et al., 1973; Edwards et al., 1973; Vàvra et al., 1968). Furthermore, it can be administered by the intranasal route. It was therefore thought suitable for testing the renal concentrating capacity (Aronson and Svenningsen, 1973).

Received 8 February 1974

\section{Material}

A total of 104 infants and children have been studied. 25 infants with birthweights ranging from $860 \mathrm{~g}$ to $4490 \mathrm{~g}$ and gestational ages from 27 to 43 weeks were studied at postnatal ages of from 1 week to 3 months, and 79 children at ages from 2 to 15 years. They were inpatients at the Department of Paediatrics in Lund, the infants for various perinatal disorders and the children for control examinations after urinary tract infection or other kidney diseases.

The following three urine concentration tests were compared: prolonged dehydration test, combined pitressin and fluid deprivation test, and finally the DDAVP test. The dehydration was compared with the DDAVP test in children only, while the pitressin test was compared with the DDAVP test in both children and infants.

\section{Methods}

Dehydration test. All fluid was withheld for 22 hours starting at 1.00 p.m. and ending the second day at 11.00 a.m. Solid food was allowed the whole time. Three to four urine specimens were collected between 6.00 and 11.00 a.m. on the second day.

Pitressin test. Children were dehydrated for 18 hours and infants for 11 hours overnight. Pitressin 
tannate in oil was administered intramuscularly 2 hours before starting fluid deprivation. Two urine specimens were collected on the following day at the end of the thirst period. The pitressin dose was $2 \mu \mathrm{g} / \mathrm{kg}$.

DDAVP test.

Preliminary studies. Before the final design of the DDAVP test (see below) had been developed, some preliminary studies were performed in order to determine the optimal dose and method of administration. Graded doses of DDAVP were given intranasally in 2 children and 1 infant. The ward nurse administered the DDAVP $(100 \mu \mathrm{g} / \mathrm{ml}$ or $400 \mu \mathrm{g} / \mathrm{ml})$ with a graded nasal tube (rhinyl). In 6 children and 5 infants the effect of DDAVP by the intranasal route $(20 \mu \mathrm{g}$ in children and 10 $\mu \mathrm{g}$ in infants) was compared with the effect of DDAVP administered intravenously $(2 \mu \mathrm{g}$ in children and 0.5 $\mu \mathrm{g} / \mathrm{m}^{2}$ in infants). During these tests urine specimens were collected 1- or 2-hourly to obtain the maximal urine osmolality.

Final design. The children were not deprived of fluid and were allowed to regulate their water intake freely. In infants the fluid intake was restricted to $50 \%$ of the ordinary intake at the two meals after administration of DDAVP in order to avoid water overload. The doses, $10 \mu \mathrm{g}$ for infants and $20 \mu \mathrm{g}$ for children, were given at 7.30 a.m. by intranasal route. After voiding at 8.30 a.m., urine specimens were collected from the children at 10.30 a.m. and 12.30 p.m., and starting 1 hour after DDAVP-administration three consecutive urine samples were collected from the infants.

Laboratory analysis. The urine osmolality was measured cryoscopically with a Fiske osmometer. Serum sodium was determined with flame photometry.

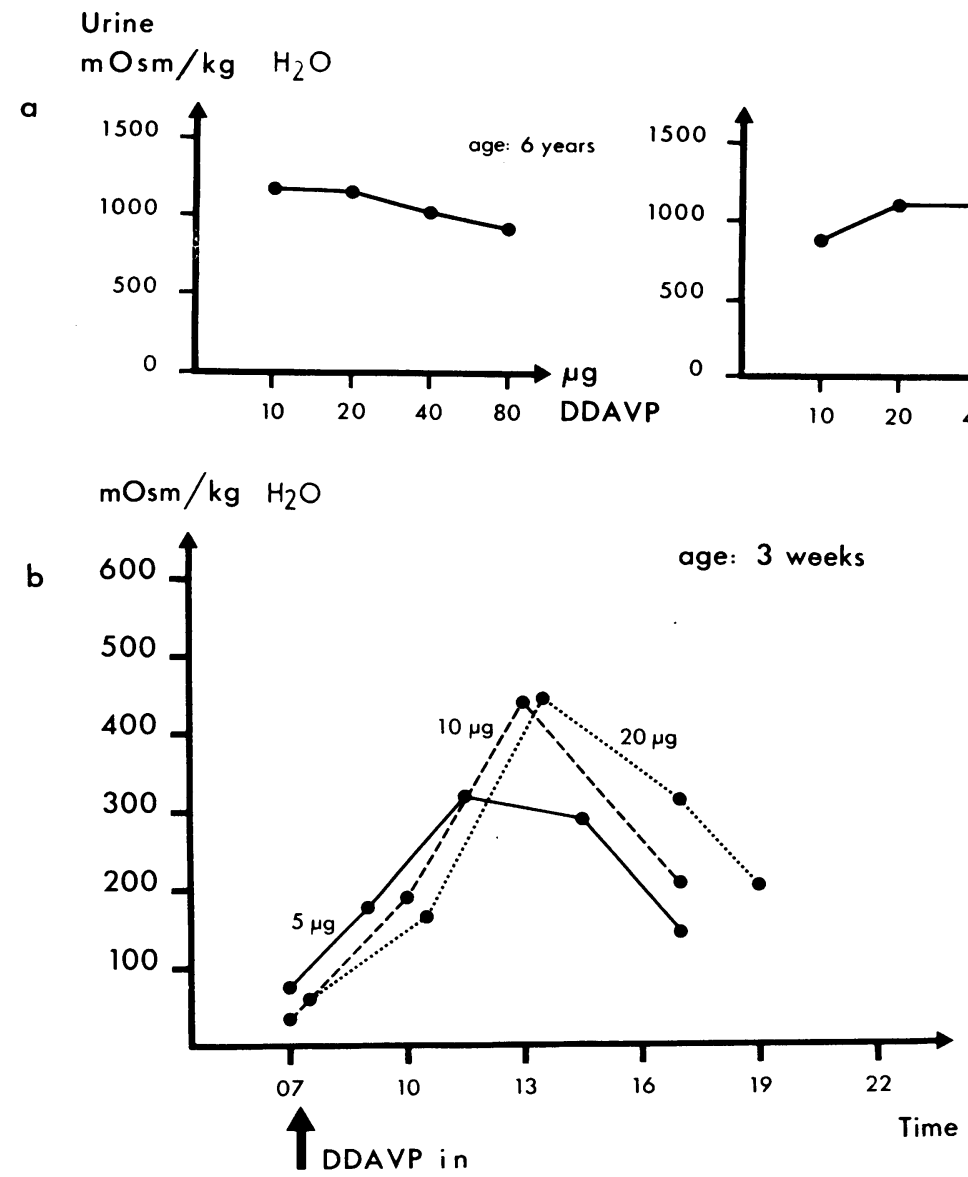

FIG. 1(a).-Maximum urine osmolality values achieved with increasing doses of intranasally administered DDAVP (10-20-40-80 $\mu \mathrm{g}$ ) in 2 children. (b) DDAVP response curve after increasing doses of intranasally administered DDAVP (5-10-20 $\mu \mathrm{g})$ in an infant. The peak value on each curve shows the maximal urine osmolality obtained after each dose of $D D A V P$. 


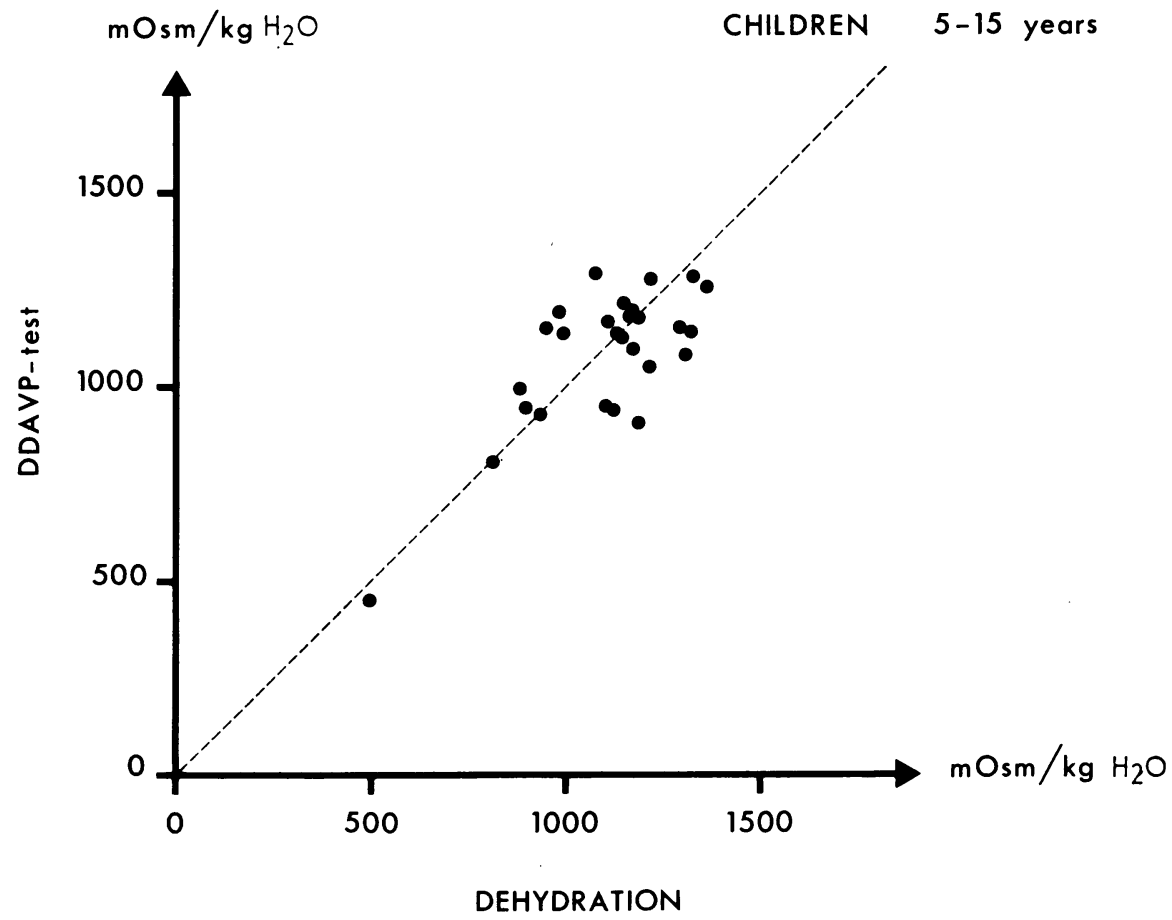

FIG. 2.-Correlation between maximum urine osmolality values after 22 hours of dehydration and $20 \mu g$ intranasally administered DDAVP, respectively, in 28 children.

\section{Results}

Comparison between different doses of DDAVP. In 2 children and 1 infant, increasing doses of DDAVP were administered intranasally, i.e. in children 10-20-40-80 $\mu \mathrm{g}$ and in infants 5-10-20 $\mu$ g. The doses were given every second or third day. As shown in Fig. 1a and b, maximum urine osmolality values were achieved after $20 \mu \mathrm{g}$ in the children and after $10 \mu \mathrm{g}$ intranasally in the infant. After these titration studies an intranasal DDAVP dose of $10 \mu \mathrm{g}$ for infants and $20 \mu \mathrm{g}$ for children was chosen in the final design of the DDAVP renal concentration performance test.

Comparison between intravenous and intranasal DDAVP administration. Intranasal as compared to intravenous administration of DDAVP was studied in 6 children aged 5 to 13 years and in 5 infants aged 4 to 6 weeks. In the children the effect of $20 \mu \mathrm{g}$ DDAVP intranasally was compared to that of $2 \mu \mathrm{g}$ intravenously. The mean maximum osmolality obtained after either way of administration was $976 \mathrm{mOsm} / \mathrm{kg}$ and $1042 \mathrm{mOsm} / \mathrm{kg}$, respectively. A similar study in the infants after administration of $10 \mu \mathrm{g}$ DDAVP intranasally and $0.5 \mu \mathrm{g} / \mathrm{m}^{2}$ intravenously resulted in mean maximum osmolality of $477 \mathrm{mOsm} / \mathrm{kg}$ and $521 \mathrm{mOsm} / \mathrm{kg}$, respectively. The differences observed were not significant ( $P>0.05$, Student's ' $t$ '-test).

Comparison between DDAVP test and dehydration test. In 28 children the DDAVP test as well as the dehydration test were performed. The maximal urine osmolality obtained in these tests are plotted in Fig. 2. In 15 children the DDAVP test resulted in higher, and in 13 children, in lower, maximum urine osmolality than after dehydration for 22 hours. There was no statistical deviation of the group values from the line of equality $(P>0 \cdot 05)$.

Comparison between DDAVP test and pitressin test. The maximum urine osmolality achieved after the DDAVP test and the pitressin test, respectively, was compared in 51 children and 25 infants. As shown in Fig. 3 there was among children a clear tendency to higher urine osmolality after the DDAVP test than after the pitressin test. 


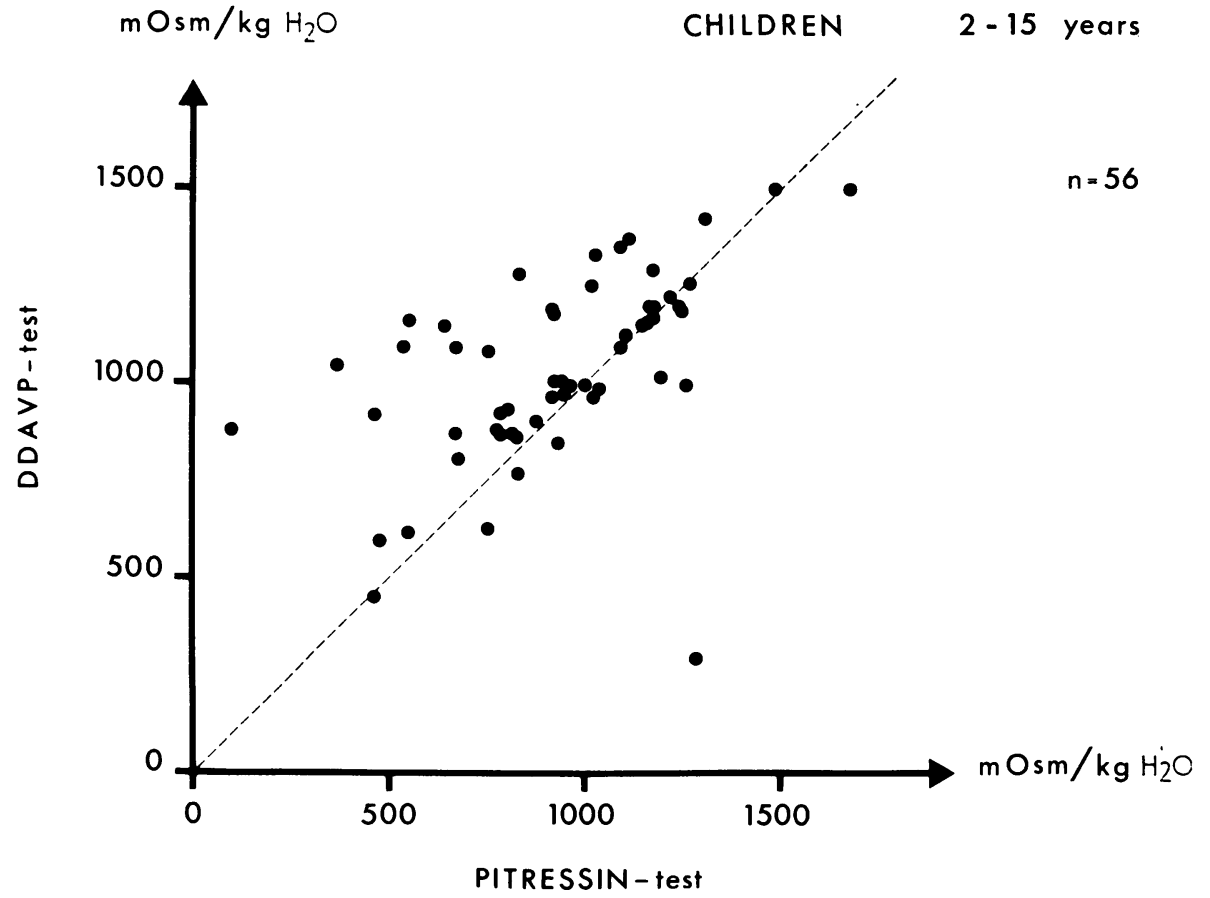

FIG. 3.-Correlation between maximum urine osmolality values during pitressin test and DDAVP test, respectively; 56 comparative measurements performed in 51 children.

The difference from the line of identity is significant $(P<0.001)$. Similar results were obtained in infants, as shown in Fig. $4(\mathrm{P}<0.001)$.

Side effects of DDAVP. In the present investigation no signs of pressor effects were observed with the DDAVP doses used. Neither were any signs of overhydration seen in the children, all regulating their water intake freely. Serum sodium values, controlled in 31 children and 13 infants, did not fall below the normal range in any case; comparison between values obtained on the day before and on the day of the DDAVP test at 1.00 p.m. showed no significant difference (mean serum sodium 140 and $139 \mathrm{mEq} / \mathrm{l}$. in children, 136 and 135 $\mathrm{mEq} / \mathrm{l}$. in infants, respectively; $\mathrm{P}>0.05)$. Among the 25 infants studied, a transient water intoxication occurred in 1 infant with a congenital heart defect. However, in this case the fluid restriction after DDAVP administration had accidentally been disregarded. In no other infant were any side effects observed.

\section{Discussion}

DDAVP for measurement of urinary concentration capacity. The effectiveness of
DDAVP, a synthetic analogue of the antidiuretic hormone, has previously been documented in diabetes insipidus in adults (Anderson and Arner, 1972; Edwards et al., 1973; Vàvra et al., 1968) and in children (Aronson et al., 1973; Kauli and Laron, 1974). It has several advantages over other antidiuretic hormone preparations, i.e. pitressin and lysine vasopressin. This was confirmed in the present investigation where DDAVP has been used for estimation of the renal urine concentrating capacity. First, in contrast to both pitressin and lysine vasopressin, DDAVP has-in clinical relevant doses-no pressor effects. Secondly, DDAVP has a long duration (6-14 hours in adults) in comparison to lysine vasopressin. Thirdly, DDAVP can be given intranasally without discomfort to the patient. The present results show that intranasal administration of DDAVP is as effective as DDAVP given intravenously. The optimal dose of DDAVP intranasally was found to be $10 \mu \mathrm{g}$ in infants and 20 $\mu \mathrm{g}$ in children: higher doses did not increase the maximal urine osmolality.

The risk of overhydration with such a potent antidiuretic hormone analogue as DDAVP must, of course, be borne in mind. In children, who are able to regulate the water intake themselves, this 


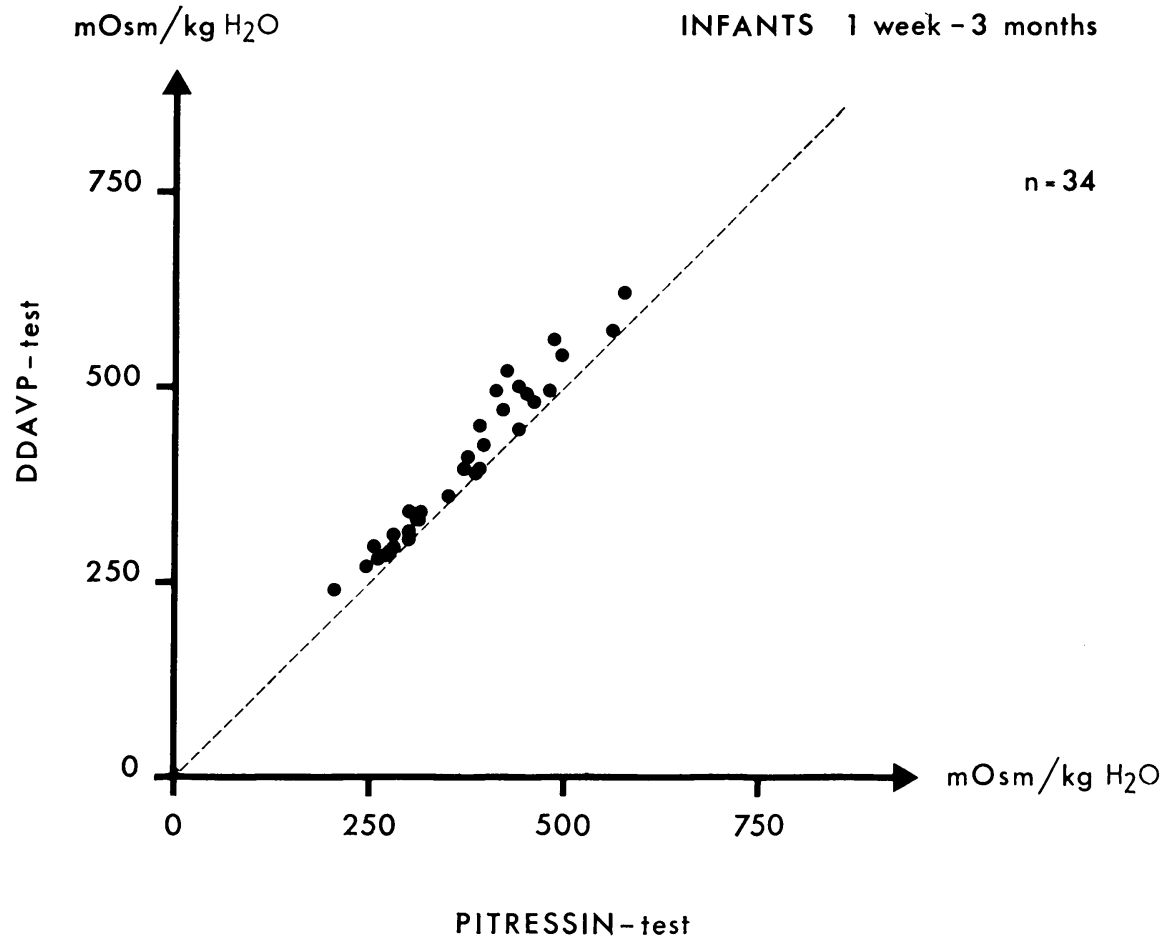

FIG. 4.-Correlation between maximum urine osmolality values during pitressin test and DDAVP test, respectively; 34 comparative measurements performed in 25 infants.

problem does not seem relevant. In fact there was in no case any lowering of the serum sodium. In small infants, however, there is a definite risk of water intoxication as observed in a single case in the present study. Yet, by restricting in bottle-fed infants the fluid intake to half the ordinary amount, the antidiuretic effect of DDAVP was approximately matched as judged by an unchanged body weight. In this way a paradoxical decrease of urine osmolality, known to develop in some cases during progressive dehydration (Miles et al., 1954; Winberg, 1959; Hinkle, Edwards, and Wolf, 1951; Miles, De Wardener, and McSwiney, 1952), could also be avoided.

DDAVP compared to other renal concentration tests. The prolonged dehydration test is a widely accepted technique for measuring the renal concentration capacity. 22 hours of dehydration has been shown to give a reasonably accurate measurement of the maximum urine osmolality (Miles et al., 1954). Thus, after 22 hours the average urine osmolality is $97 \%$ of the maximum urine osmolality obtained after 26 hours of dehydration. As shown in the present investigation, the urine osmolality after intranasally administered DDAVP rises to values of the same order as after 22 hours of prolonged dehydration. Yet, the DDAVP test has obvious advantages in comparison to dehydration tests. In infants only a short period of moderate fluid restriction is necessary, and children can be tested without any dehydration at all. Furthermore, urine has to be collected only for a few hours.

In comparison to the pitressin test the DDAVP test also seems advantageous, since there is no need for a real fluid deprivation as in the pitressin test (West et al., 1955; Winberg, 1959) in order to obtain near maximum levels of urine osmolality. The intranasal administration of DDAVP is also preferable to the often painful intramuscular administration of pitressin tannate in oil. Furthermore, the risk of sensitization, which has been described with the use of pitressin (Osváth et al., 1970; Roth et al., 1966), is avoided. Finally, the maximum urine osmolality obtained in both infants 
and children is generally higher after the DDAVP test than after the pitressin test (Fig. 3 and 4 ). Consequently, the DDAVP test seems to be a reliable and feasible method in infants and children for measuring the renal concentrating capacity.

We thank Dr. Jan Mulder at Ferring AB, Malmö, Sweden, for the supply of DDAVP, and Miss Margaretha Håkanson for assistance.

\section{REFERENCES}

Anderson, K. E., and Arner, B. (1972). Effects of DDAVP, a synthetic analogue of vasopressin, in patients with cranial diabetes insipidus. Acta Medica Scandinavica, 192, 21.

Aronson, A. S., Anderson, K. E., Bergstrand, C. G., and Mulder, J. L. (1973). Treatment of diabetes insipidus in children with DDAVP, a synthetic analogue of vasopressin. Acta Paediatrica Scandinavica, 62, 133.

Aronson, A. S., and Svenningsen, N. W. (1973). A new synthetic vasopressin derivate, DDAVP, in the evaluation of renal concentration capacity. Proceedings of the European Society of Pediatric Endocrinology, 12th Annual Meeting, Bergen, June 1973, p. 46.

Edelmann, C. M., Jr., Barnett, H. L., Stark, H., Boichis, H., and Rodriguez Soriano, J. (1967). A standardized test of renal concentrating capacity in children. American fournal of Diseases in Children, 114, 639.

Edwards, C. R. W., Kitau, M. J., Chard, T., and Besser, G. M. (1973). Vasopressin analogue, DDAVP, in diabetes insipidus; clinical and laboratory studies. British Medical fournal, 3, 375.

Hinkle, L. E., Jr., Edwards, C. J., and Wolf, S. (1951). Occurrence of diuresis in humans in stressful situations and its possible relation to the diuresis of early starvation. Fournal of Clinical Investigation, 30, 809.
Jones, R. V. H., and de Wardener, H. E. (1956). Urine concentration after fluid deprivation or pitressin tannate in oil. British Medical fournal, 1, 271.

Kauli, R., and Laron, Z. (1974). A vasopressin analogue in treatment of diabetes insipidus. Archives of Disease in Childhood, 49, 483.

Miles, B. E., de Wardener, H. E., and McSwiney, R. R. (1952). Renal function during emotional diuresis. American fournal of Medicine, 12, 659.

Miles, B. E., Paton, A., and de Wardener, H. E. (1954). Maximum urine concentration. British Medical fournal, 2, 901.

Osváth, P., Kovács, K., Lerchner, J., and Godó, B. (1970). Development of atopic allergy to synthetic lysine vasopressin in a child suffering from Hand-Schüller-Christian disease. Allergie und Asthma, 16, 97.

Polàcek, E., Vocel, J., Neugebauerová, L., Šebková, M., and Věchetóva, E. (1965). The osmotic concentrating ability in healthy infants and children. Archives of Disease in Childhood, 40, 291.

Roth, J., Glick, S. M., Klein, L. A., and Petersen, M. J. (1966). Specific antibody to vasopressin in man. Fournal of Clinical Endocrinology, 26, 671.

Vàvra, I., Machová, A., Holecèk, V., Cort, J. H., Zaoral, M., and Sorm, F. (1968). Effect of a synthetic analogue of vasopressin in animals and in patients with diabetes insipidus. Lancet, 1, 948.

West, C. D., Traeger, J., and Kaplan, S. A. (1955). A comparison of the relative effectiveness of hydropenia and of pitressin in producing a concentrated urine. Fournal of Clinical Investigation, 34, 887.

Winberg, J. (1959). Determination of renal concentration capacity in infants and children without renal disease. Acta Paediatrica Scandinavica, 48, 318.

Correspondence to Dr. A. S. Aronson, Barnkliniken, Lasarettet, S-221 85 Lund, Sweden. 